\title{
Emprego da resina acrílica ou da dermorrafia na oclusão da ferida após a descorna em bovinos adultos a campo
}

\author{
Comparison between two occlusion techniques of dehorning wounds in adult \\ cattle under field conditions
}

\author{
Ariane Paula Rovani Scolari ${ }^{[a]}$, Camila Sloboda Pacheco da Silva ${ }^{[a]}$, Felipe Pencai ${ }^{[a]}$, \\ Tatiana Figueiredo ${ }^{[a]}$, Thaís Turra ${ }^{[a]}$, Rüdiger Daniel Ollhoff ${ }^{[b]}$
}

[a] Médico(a) veterinário(a), Mestrando em Ciência Animal da Pontifícia Universidade Católica do Paraná (PUCPR), Curitiba, PR - Brasil, e-mails: thaturra@hotmail.com; scolariapr@gmail.com; camilasloboda@gmail.com; fwpencai@terra.com.br; figueiredotati@hotmail.com

[b] Médico Veterinário, professor Doutor do curso de Medicina Veterinária da Pontifícia Universidade Católica do Paraná (PUCPR), São José dos Pinhais, PR - Brasil, e-mail: daniel.ollhoff@pucpr.br

\section{Resumo}

O objetivo deste estudo foi comparar duas técnicas de descorna a campo em bovinos adultos, empregandose a técnica padrão da dermorrafia e outra, mediante o uso da resina acrílica, com vistas à exequibilidade de sua utilização a campo. Foram utilizados seis animais mestiços, pesando entre 332 e 469 kg, empregandose uma técnica em cada corno, escolhendo o lado de modo aleatório. A fase de preparação, bem como a própria cirurgia, foi cronometrada. A técnica da dermorrafia consistiu de incisão da pele de modo elíptico em torno da base cornual, divulsionando-se o tecido mole até que fosse possível a amputação do corno com fio serra de Liess. A técnica em que se utilizou a resina acrílica foi executada com o fio serra de Liess e a oclusão da cavidade com metilacrilato. A média da circunferência da base do corno esquerdo foi de 19,7 cm e do lado direito, de 19,6 cm. O tempo médio gasto para a técnica da dermorrafia foi de 36,9 minutos, e o da resina, de 7,7 minutos $(\mathrm{p}<0,02)$. Um animal apresentou epistaxe bilateral três dias após a cirurgia. Catorze dias após os procedimentos cirúrgicos, a cicatrização da pele em ambos os métodos evoluíram clinicamente de modo satisfatório. Concluiu-se que a oclusão da cavidade do seio cornual a campo com a resina possibilitou maior praticidade e rapidez, recomendando-se o seu emprego.

Palavras-chave: Descorna. Seio cornual. Dermorrafia. Resina acrílica. Bovinos adultos. 


\begin{abstract}
The purpose of this study was to compare two dehorning techniques in adult cattle, the standard dehorning technique performed in six horns of six adult cattle and the alternative closure of the sinus with acrylic resin in the other six horns of the same crossbreed animals, weighing between 332 and $469 \mathrm{~kg}$. Preparation of the surgery as well as the intervention itself was time measured. The standard technique consisted of an elliptical skin incision around the horn basis, tissue undermining and horn amputation with a Liess saw and afterwards skin closure; the alternative dehorning technique was performed using only the saw and the opened sinus was closed with resin. The horn basis circumference measured $19.75 \pm 1.2 \mathrm{~cm}$ on the left and $19.67 \pm 1.03 \mathrm{~cm}$ on the right side. The time spent for the standard technique was $36.97 \pm 25.65$ minutes; for the resin method $7.72 \pm 1.83$ minutes $(p<0,025)$. One animal showed bilateral epistaxis 3 days after surgery as the only occurrence observed in a 14 days period. It was concluded that the occlusion with resin is in such a way more fast of being carried out then it offers little animal suffering, being the most recommended in dehorning of bovines under field conditions.
\end{abstract}

Keywords: Dehorning. Cornual sinus. Acrylic resin. Surgery. Cattle.

\title{
Introdução
}

A descorna de bovinos adultos é uma cirurgia consideravelmente invasiva, caracterizada por elevação expressiva dos níveis de cortisol (STAFFORD, 2005). Porém, faz-se necessária, principalmente, em casos da agressividade de um animal perante outros ou perante o homem, nos casos de fraturas do corno ou de cornos de conformação anormal (WEAVER, 1986; DIRKSEN; GRUNDER; STOBER. 2002). A descorna evita frequentemente as lacerações e as perfurações de pele, aumentando a qualidade do couro (FIORAVANTI et al., 1999), além de viabilizar o manejo e a uniformização do rebanho, ao requerer menor espaço nos cochos durante a alimentação (HELOU et al., 2008).

Entre as técnicas utilizadas para a descorna cirúrgica, é possível citar diferentes técnicas de dermorrafia (SILVEIRA, 1984; WEAVER, 1986; FIORAVANTI et al., 1999; CUNHA et al., 2002) ou então a oclusão do seio cornual aberto com diferentes materiais sintéticos (metilmetacrilato e filmes sintéticos associados ao algodão) (MADERMACHER; HENNINGER, 1996). A descorna em bovinos adultos consiste em uma cirurgia cruenta, que se não for devidamente realizada, pode ocasionar problemas graves no decorrer da cirurgia ou no pós-operatório. No pós-operatório observa-se comumente a deiscência dos pontos cirúrgicos, em função da tensão exagerada na linha de sutura, além de febre, letargia, anorexia, postura anormal da cabeça, deformação dos ossos frontais, secreção nasais mucopurulenta, distúrbios neurológicos, exoftalmia (SMITH, 1993) e sinusites (SILVA et al., 2008). A sinusite é um processo inflamatório que acomete os seios do crânio, ocorrendo com maior frequência nos bovinos, após realização de descorna cirúrgica estética ou mochação com ferro candente, expondo o seio frontal (JUBB; KENNEDY; PALMER, 1990; BLOOD; RADOSTITS, 1991).

Fatores relacionados à antissepsia e assepsia, realizações de intervenções cirúrgicas por pessoas inabilitadas, presença de corpos estranhos e pós-operatório conduzido de forma inadequada são mencionados como importantes fatores na etiopatogenia do processo em bovinos (FIORAVANTI et al., 1996).

Este experimento teve como objetivo comparar duas técnicas de descorna cirúrgica em bovinos: a descorna com o uso da dermorrafia e a descorna cosmética com oclusão do seio com resina acrílica, relativamente ao tempo decorrido em cada procedimento e seus pós-operatórios, à necessidade de material cirúrgico e a caracterização do animal após a cicatrização.

\section{Material e métodos}

O estudo foi desenvolvido pelos alunos do Mestrado em Ciência Animal, da Pontifícia Universidade Católica do Paraná (PUCPR), em uma propriedade rural, no município de Fazenda Rio Grande, PR, utilizando 
seis bovinos, mestiços (Bos taurus/Bos indicus), com idade aproximada de 2,5 anos e peso corporal médio de $408 \mathrm{~kg}$ (332 a $469 \mathrm{~kg}$ ), com base dos cornos no tamanho médio de 19,75 \pm 1,2 cm (cornos esquerdos) e $19,67 \pm 1,03 \mathrm{~cm}$ (cornos direitos) de diâmetro. Nos seis bovinos foram realizadas as duas técnicas, uma em cada corno, sendo os lados escolhidos de maneira aleatória. Por uma questão de facilidade, o primeiro corno sempre foi retirado por meio de descorna com dermorrafia (A) e o segundo, com o uso da resina (B).

Nas duas técnicas de descornas foi utilizado o seguinte instrumental cirúrgico: tricótomo, lâmina de barbear, luvas estéreis, cabo de bisturi n. 4, lâmina n. 24, tesoura ponta romba, fio serra de Liess previamente esterilizado, pinças hemostáticas, gazes estéreis e, no caso da dermorrafia, a agulha traumática para sutura em formato de "S" com 4 polegadas de comprimento.

Foi realizada sedação com cloridrato de xilazina $2 \%$ (Rompun ${ }^{\circledR}$ - Bayer) via intramuscular na dose de $0,1 \mathrm{mg} / \mathrm{kg}$, facilitando a contenção física com cordas, mantendo o animal em decúbito esternal durante toda a cirurgia. Na sequência, fez-se a tricotomia nos dois cornos, assim como a assepsia com solução de clorexidine a $0,5 \%$. Após esse procedimento, iniciou-se a anestesia com cloridrato de lidocaína a 2\% (Lidovet ${ }^{\circledR}$ - Bravet), administrada no arco zigomático, atingindo o nervo cornual e complementando com anestesia circular ao redor da base do corno. O tempo da tricotomia (T1), da assepsia (T2), da anestesia (T3) e das cirurgias (TA e TB) foi medido com uso de um cronômetro.

No método A realizou-se uma incisão na parte látero-rostral do chanfro, associada à incisão semicircular na base do processo córneo, seguindo para a divulsão entre pele e subcutâneo, conforme Turner; Mcllwraith (1985) e Weaver (1986). Após essa etapa, efetuou-se a secção da base maior do corno com fio serra, utilizando-se a torção do próprio corno para a hemostasia da veia cornual, além de 3,5 g de penicilina (Pencivet ${ }^{\mathbb{B}}$ - Intervet) em pó pulverizados para dentro do seio como medida profilática. A sutura foi realizada com fio inabsorvível (algodão Urso ${ }^{\circledR}$ 0000), em padrão interrompido simples, e, ao finalizar, foi aplicado no local um aerossol (Organnact Prata ${ }^{\circledR}$ - Chemiker do Brasil) com efeito cicatrizante, repelente e larvicida.

No corno oposto, o método B, foi realizado com os mesmos cuidados de tricotomia, assepsia e anestesia do método A. A incisão na pele foi semilunar na porção rostral do corno, a cerca de $1 \mathrm{~cm}$ do fim do tecido corneificado duro, somente para suporte e guia do fio serra. Após a secção do corno, profilaxia antibiótica conforme método A, assentou-se a resina de metil metacrilato (Jet ${ }^{\circledR}$ Clássico - Artigos Odontológicos Clássicos Ltda.) na superfície óssea exposta, precavendo-se para não entrar em contato com a pele, apoiandose somente sob a estrutura óssea, permitindo-se escorrer um pouco da resina para dentro do seio aberto, visando a uma melhor ancoragem. No pós-operatório, os animais foram acompanhados no $3^{\circ}, 5^{\circ}$ e $14^{\circ}$ dia, avaliando-se por meio da inspeção o estado geral do bovino e o local da ferida. O tempo decorrido durante as fases dos procedimentos A e B e T1 a T3 foram medidos e organizados em bases de dados para a análise estatística. Calculou-se a média e o desvio padrão, com as amostras de tempo pareadas, inicial e final, para a tricotomia (T1), assepsia (T2) e anestesia (T3). O delineamento escolhido para o tratamento dos dados referentes ao tempo dos métodos A e B foi o teste não paramétrico de Wilcoxon realizado em software estatístico GraphPad Prism versão 3.00 para Windows ${ }^{\circledR}$.

\section{Resultados e discussão}

Os respectivos tempos de tricotomia, assepsia e anestesia, assim como o tempo despendido nas duas diferentes técnicas cirúrgicas, estão na Tabela 1. As diferenças entre os tempos da cirurgia com dermorrafia (TA) e com uso da resina (TB) foram expressivas ( $p<0,025)$.

A descorna utilizando-se o metilmetacrilato, além do menor tempo, provocou menor hemorragia e, portanto, menor necessidade de uso de materiais cirúrgicos de apoio, como as pinças hemostáticas. Isso acarreta menor custo e tempo de preparo de material para a descorna com uso de resina sintética. A menor manipulação do tecido (ausência do processo de divulsão do tecido) garante também condições para melhor recuperação (MADERMACHER, 1996), inclusive por ofertar menor superfície lesional e menor tempo de exposição aos contaminantes provenientes do meio ambiente, como é previsível em uma cirurgia 
realizada a campo. A este respeito, a bibliografia consultada concentra-se em estudos com enfoque em bezerros e no bem-estar animal (VICKERS et al., 2005; HEINRICH et al., 2009). No presente estudo empregou-se esta técnica mensurando-se exatamente a duração do ato cirúrgico. Silveira (1984), realizando a dermorrafia com fio cirúrgico, mediu a duração da síntese cirúrgica, obtendo em 50 vacas mestiças, o tempo de três minutos, sem variação neste tempo. A ausência de variação em um número considerável de indivíduos, como no caso de Silveira (1984), é pouco provável, levantando-se questionamentos sobre este dado. Ressalte-se que esse autor não mensurou o tempo de preparo e o tempo de amputação do corno ao utilizar uma serra com arco.

Tabela 1 - Duração das cirurgias de descorna bovina adulta empregando-se a técnica da dermorrafia (A) e da oclusão com resina (B)

\begin{tabular}{lcc}
\hline Métodos & $\begin{array}{c}\text { Duração (média) } \\
\text { (minutos e segundos) }\end{array}$ & $\begin{array}{c}\text { Desvio padrão } \\
\text { (minutos e segundos) }\end{array}$ \\
\hline Tricotomia (T1)(n= 12) & $11^{\prime} 07^{\prime \prime}$ & $8^{\prime} 21^{\prime \prime}$ \\
Assepsia (T2)(n= 12) & $2^{\prime} 00^{\prime \prime}$ & $1^{\prime} 35^{\prime \prime}$ \\
Anestesia (T3)(n= 12) & $6^{\prime} 11^{\prime \prime}$ & $2^{\prime} 3^{\prime \prime}$ \\
Cirurgia A ( $=6)$ & $36^{\prime} 97^{\prime \prime} \mathrm{a}$ & $25^{\prime} 65^{\prime \prime} \mathrm{a}$ \\
Cirurgia B (n=6) & $7^{\prime} 72^{\prime \prime} \mathrm{b}$ & $1^{\prime} 83^{\prime \prime} \mathrm{b}$ \\
\hline
\end{tabular}

Nota: a,b - letras diferentes na mesma coluna diferem para $\mathrm{p}<0,02$.

A ausência de fistulas e secreções de aspecto purulento fluindo pelas narinas e de sinais clínicos sistêmicos foi considerado por Silva et al. (2008) como cura clínica completa. Considerando a definição de Silva et al. (2008), todos os animais operados foram considerados curados após o término do tempo de observação. Em um animal observou-se epistaxe no terceiro dia, e em ambas as narinas. Portanto, foi decorrente de hemorragias causadas pelas duas técnicas empregadas. Como houve somente esta ocorrência, ambas as técnicas foram consideradas adequadas no quesito recuperação pós-cirúrgica.

Alguns fatores podem influenciar a obtenção de bons resultados em relação às duas técnicas utilizadas. Assim, a tricotomia reveste-se de especial importância, pois ela delimita a uniformidade do local da amputação. Para Fioravanti et al. (1999), deve-se considerar a raça e a conformação da cabeça, para que como resultado final não haja a descaracterização do animal. A assepsia também se constitui em etapa primordial e que deve ser bem executada para evitar infecções dos tecidos durante as intervenções cirúrgicas. Todo o procedimento deve ser realizado somente depois de adequada contenção física e sedação química. Observa-se na Tabela 1 que o tempo utilizado para o preparo (tricotomia, assepsia e anestesia) aproxima-se de meia hora, ou seja, é quase tão moroso quanto a própria intervenção cirúrgica A. Como este estudo é o primeiro a mensurar separadamente estas etapas, é o primeiro a evidenciar a possibilidade de aprimoramento delas, ressaltando-se ser fundamental um bom planejamento prévio. É má prática e deve ser evitado, após a contenção do animal, proceder-se ao preparo do material estendendo-se desnecessariamente sua manipulação. A busca pela melhoria contínua desta intervenção de descorna em bovino adulto mostra-se corriqueira na prática buiátrica, e poderá ser objetivo de estudos futuros. Tratando-se da técnica com resina acrílica, é muito importante que a colocação da resina fique em contato apenas com a porção óssea da cavidade onde existia o corno, facilitando assim a cicatrização da ferida cirúrgica. Estudos prévios realizados por Ollhoff (2009 - comunicação oral) haviam demonstrado que a permanência de uma capa acrílica sobrepondo-se à pele impedia a cicatrização plena e facilitava a instalação de infecção, induzindo ao prurido, à hemorragia e à miíase, assim como sinusites 
subsequentes. Do ponto de vista estético, o emprego da resina apresenta um resultado pior que a dermorrafia, em função da permanência de segmento do corno incompletamente coberto pelos pêlos. No $14^{\circ}$ dia após a cirurgia foram retirados os pontos da dermorrafia, sem alterações. Nenhum animal apresentou sinais de alterações comportamentais ou sinusite.

Concluiu-se que a descorna de bovino adulto utilizando-se a oclusão do seio com metilmetacrilato mostrou-se uma técnica rápida e eficaz. A descorna com dermorrafia mostrou-se mais trabalhosa, tornando o animal mais suscetível a contaminações, em função da maior manipulação a campo, além da necessidade de retirada dos pontos. Entretanto, é a técnica com resultado esteticamente melhor. A cirurgia utilizando a técnica com resina demonstrou ser mais rápida que a técnica com sutura da pele, além de poder ser empregada em animais com pouca pele ou com base do corno larga, como o é em zebuínos.

\section{Referências}

BLOOD, D. C.; RADOSTITS, O. M. Clínica veterinária. 7. ed. Rio de Janeiro: Guanabara Koogan, 1991.

CUNHA, O. et al. Nova técnica para descorna em bovinos. Arquivos de Ciências Veterinárias e Zoologia da UNIPAR, v. 5, n. 1, p. 59-63, 2002.

DIRKSEN, G.; GRÜNDER, H. D.; STÖBER, M. Innere medizin und chirurgie des rindes. Berlin, Wien: Paul Parey Verlag, 2002.

FIORAVANTI, M. C. S. et al. Tratamento de abscessos cutâneos com ácido metacresolsulfônico associado à nitrofurazona e a aplicação parenteral de enrofloxacina. In: CONGRESSO PANAMERICANO DE CIÊNCIAS VETERINÁRIAS, 15., 1996, Campo Grande. Anais... Campo Grande: Congresso Panamericano de Ciências Veterinárias 1996. p. 187-187.

FIORAVANTI, M. C. S. et al. Descorna de bovinos utilizando grampos de metal na dermorrafia. Ciência Rural, v. 29, n. 3, p. 507-510, 1999.

JUBB, K. V. F.; KENNEDY, P. C; PALMER, N. Patologia de los animales domesticos. Montevideo: Hemisferio Sur. 1990.

HEINRICH, A. et al. The impact of meloxicam on postsurgical stress associated with cautery dehorning. Journal of Dairy Science, v. 92, p. 540-547, 2009.

HELOU, J. B. et al. Descorna plástica em bovinos: uso tópico de um composto a base de quitosana a 5\% como auxiliar na cicatrização de feridas. In: CONGRESSO BRASILEIRO DE MEDICINA VETERINÁRIA, 35., 2008, Gramado, RS. Anais... Gramado, RS: Congresso Brasileiro de Medicina Veterinária, 2008.

SILVEIRA, J. M. D. Novo método de descorna em bovino adulto. 1984. 28 f. Dissertação (Mestrado Medicina Veterinária) - Universidade Federal de Minas Gerais, Belo Horizonte, 1984.

MADERMACHER, R.; HENNINGER, W. Verschluß der stirnhöhlen nach der enthornung adulter rinder. Wiener Tierärztliche Monatsschrift, v. 83, n. 9, p. 255-262, 1996.

OLLHOF, R. D. Tópicos especiais em Buiatria. Fazenda Rio Grande: PUCPR, 2009. (Comunicação oral).

SILVA, L. A. F. et al. Estudo retrospectivo sobre fatores de risco e avaliação de quatro protocolos terapêuticos para sinusite em um rebanho de 2492 bovinos (1998-2008). In: CONGRESSO BRASILEIRO DE MEDICINA VETERINÁRIA, 35., 2008, Gramado, RS. Anais... Congresso Brasileiro de Medicina Veterinária, Gramado-RS, 2008.

SMITH, B. P. Tratados de medicina interna dos grandes animais. São Paulo: Manole, 1993.

STAFFORD, K. J.; MELLOR, D. J. Dehorning and disbudding distress and its alleviation in calves. The Veterinary Journal, v. 53, p. 271-278, 2005.

TURNER, A. S.; MCLLWRAITH, C. W. Técnicas cirúrgicas em animais de grande porte. São Paulo: Roca, 1985. 
VICKERS, K. J. et al. Calf response to caustic paste and hot-iron dehorning using sedation with and without local anesthetic. Journal of Dairy Science, v. 88, p. 1454-1459, 2005.

WEAVER, A. D. Bovine surgery and lameness. Melbourne: Blackwell Scientific Publications, 1986.

Recebido: $21 / 03 / 2010$

Received: 03/21/2010

Aprovado: $12 / 05 / 2010$

Approved: 05/12/2010

Rev. Acad., Ciênc. Agrár. Ambient., Curitiba, v. 8, n. 3, p. 347-352, jul./set. 2010 